\title{
Synthesis and Thermal Decomposition Behavior of Zircoaluminate Coupling Agents
}

\author{
Bin $\mathrm{Li}^{*},{ }^{\dagger, \ddagger}$ Hongyan Mou, ${ }^{\dagger, \S}$ Youming $\mathrm{Li}^{*}{ }^{* \dagger}$ and Yonghao $\mathrm{Ni}^{\|}$ \\ ${ }^{\dagger}$ State Key Laboratory of Pulp and Paper Engineering, South China University of Technology, Guangzhou 510640, China \\ ${ }^{\ddagger}$ Key Laboratory of Biofuels, Qingdao Institute of Bioenergy and Bioprocess Technology, Chinese Academy of Sciences, Qingdao \\ 266101, China \\ ${ }^{\S}$ Laboratory of Fibre and Cellulose Technology, Åbo Akademi University, Turku 20500, Finland \\ "Department of Chemical Engineering and Limerick Pulp \& Paper Centre, University of New Brunswick, Fredericton, New \\ Brunswick, E3B 5A3, Canada
}

\begin{abstract}
Zircoaluminate coupling agents can be used as surface modifiers or adhesion additives in many applications, such as plastics, rubbers, coatings, and pigments. In this paper, a range of zircoaluminates with different functional groups were synthesized, by using polyaluminum chloride (PAC), zirconium oxychloride, 1,2-propanediol, and others. The products were characterized by FTIR, MALDI-TOF MS (matrix-assisted laser desorption/ionization time-of-flight mass spectrometry), and TGA. FTIR spectra indicated that the multiple bands at $1636-1567 \mathrm{~cm}^{-1}$ are the characteristics of zircoaluminates. The numberaverage molecular weight and weight-average molecular weight of carboxyl functional zircoaluminate (sample ZA-C6) are 2125 and $2295 \mathrm{~g} / \mathrm{mol}$, respectively, as determined by MALDI-TOF MS. The molar ratio of reactants and selected organofunctional ligands can affect not only the properties but also the thermal stabilities of final products. TGA results showed that the decomposition of zircoaluminates includes four distinct stages and dodecyl functional zircoaluminate (sample ZA-F) has the highest decomposition temperature of $374^{\circ} \mathrm{C}$.
\end{abstract}

\section{INTRODUCTION}

Zircoaluminate coupling agent is one of the low-molecularweight inorganic polymers, and it is usually composed of three parts: the chelated aluminum moiety, the organofunctional ligand, and the zirconium moiety. ${ }^{1}$ Typically, the empirical formula of a zircoaluminate coupling agent can be represented as $^{2}$

$$
\left[\mathrm{Al}_{2}\left(\mathrm{OR}_{1} \mathrm{O}\right)_{a} \mathrm{~A}_{b} \mathrm{~B}_{c}\right]_{X}\left[\mathrm{OC}\left(\mathrm{R}_{2}\right) \mathrm{O}\right]_{Y}\left[\mathrm{ZrA}_{d} \mathrm{~B}_{e}\right]_{Z}
$$

wherein $\mathrm{A}$ or $\mathrm{B}$ can be halogen (generally chlorine) or hydroxyl; $X, Y$, and $Z$ may range from 1 to 100 or more; $2 a+b$ $+c=4 ; d+e=2$. There are two different kinds of organic ligands selectively bounded to the backbone of zircoaluminates: (1) one ligand $\left(\mathrm{OR}_{1} \mathrm{O}\right)$ imparts the hydrolytic and hydroxylic stability to its inorganic portion, and it can be $\alpha, \beta$ - or $\alpha, \gamma$-glycol, or $\alpha$-hydroxycarboxylic acid, and with no more than six carbon atoms; (2) the other $\left(\mathrm{OC}\left(\mathrm{R}_{2}\right) \mathrm{O}\right)$ contributes organofunctionality or reactivity to the zircoaluminates, and it can include carboxyl, hydroxyl, mercapto, amino, or oleophilic groups, etc. for different purposes. Also, zirconium has less affinity than aluminum does due to its bigger atomic size, but it is critical to the stability of zircoaluminates. ${ }^{3}$

Cohen ${ }^{1-3}$ first synthesized a zircoaluminate coupling agent and studied its applications as a surface modifier and an adhesion promoter. Since then, zircoaluminates have been widely used in plastics, rubbers, coatings, pigments, adhesives, etc. It was reported that zircoaluminates are less water sensitive (unlike silanes and titanates) and cost-effective in the irreversible modification of all inorganic fillers/pigments, carbon black, and many organic pigments, leading to significant viscosity reduction of coating resin or solvent and reducing particle agglomeration. ${ }^{3-6}$ Also, zircoaluminates can improve salt spray resistance, ${ }^{4}$ enhance adhesion to coatings or metal substrates, ${ }^{7-9}$ reduce corrosion of many metallic materials, ${ }^{4,5}$ and increase water resistance, ${ }^{10}$ thus prolonging the service life of end products, such as solvent- and waterborne coatings.

Recently, a cationic-functional zircoaluminate was synthesized by Chen et al., ${ }^{11}$ and they demonstrated that the cationic zircoaluminates can efficiently improve the retention of precipitated calcium carbonate during papermaking and enhance paper physical properties. ${ }^{12}$ In addition, zircoaluminates can also be used as surface modifiers of nanoparticles, such as nano- $\mathrm{ZrO}_{2},{ }^{13}$ nano- $\mathrm{CaCO}_{3}{ }^{14-18}$ and nano- $\mathrm{TiO}_{2}{ }^{19-21}$ It has been reported that about $50 \%$ reduction of the viscosity of a nano- $\mathrm{TiO}_{2}$ aqueous slurry ( $30 \%$ solid content) can be achieved after the surface modification using $0.4 \mathrm{wt} \%$ carboxyl functional zircoaluminates. ${ }^{21}$ It is also demonstrated that a better microscopic pore structure of a paper coating surface can be obtained when carboxyl zircoaluminate modified nano- $\mathrm{TiO}_{2}$ was added to the paper coating, and the resulting coated paper had improved optical properties and printability. ${ }^{22}$

However, most of studies are focused on applications, and the characterization of zircoaluminates is scarcely reported. This may be due to the complex molecular structure of zircoaluminates. Previous studies based on Fourier transform infrared (FTIR) analysis indicated that there is a $\pi$ bond ( $\mathrm{O}-$ $\mathrm{C}-\mathrm{O}$ ) structure between $\mathrm{Al}$ and $\mathrm{Zr}$ in zircoaluminates. ${ }^{14,23}$

Received: March 19, 2013

Revised: July 28, 2013

Accepted: August 2, 2013

Published: August 2, 2013 
Although it was reported that zircoaluminate coupling agent has a low molecular weight, ${ }^{5,21}$ no exact value is available in the literature. Also, previous reports just indicated that the decomposition temperature of zircoaluminates is above 300 ${ }^{\circ} \mathrm{C},{ }^{21,23}$ but the detailed thermal decomposition behavior has not been reported, particularly for the various products with different molar ratios of 1,2-propanediol to $\mathrm{Al}$, different molar ratios of chelated polyaluminum chloride (PAC) to $\mathrm{Zr}$, or different functional groups. In the present paper, a range of zircoaluminates with different functional groups were synthesized, their general properties were determined, and their thermal decomposition behaviors were studied.

\section{EXPERIMENTAL SECTION}

2.1. Materials. Polyaluminum chloride (PAC) with a basicity of about $86 \%$ and $\mathrm{Al}_{2} \mathrm{O}_{3}$ content of $25.7 \mathrm{wt} \%$ was received from Gongyi City Fuyuan Water Purification Materials Co. Ltd. (China). Hydrochloric acid, nitric acid, zirconium oxychloride, 1,2-propanediol, methanol, isopropyl alcohol, adipic acid, methacrylic acid, and lauric acid were all of analytical reagent grade. Dodecyl dimethyl betaine with $30 \pm 1$ wt \% solid content was supplied by Guangzhou Liangpeng Chemical Industry Co. Ltd. (China), and its molecular structure is shown as follows:

$$
\mathrm{C}_{12} \mathrm{H}_{25}-{\stackrel{\mathrm{C}}{\mathrm{C}}-\mathrm{CH}_{3}}_{\mathrm{CH}_{3}}^{\mathrm{COO}^{-}}
$$

All materials were used as received, without further purification.

2.2. Preparation of Zircoaluminates. On the basis of Cohen's studies ${ }^{1,2}$ and our early studies, ${ }^{20,21,24}$ the synthesis of zircoaluminates was designed as follows: (1) the organic ligand $\mathrm{OR}_{1} \mathrm{O}$ was chelated to the backbone of PAC, to enhance the hydrolytic and hydroxylic stabilities of the final products (it is noted that PAC is a common cationic polymer used in the paper industry ${ }^{25}$ ); (2) the chelated PAC was bridged to zirconium oxychloride through the organofunctional ligand $\left(\mathrm{OC}\left(\mathrm{R}_{2}\right) \mathrm{O}\right)$. PAC is mainly based on the $\mathrm{Al}_{13}$ units, ${ }^{26,27}$ and can be generally represented by the empirical formula of $\left[\mathrm{Al}_{2}(\mathrm{OH})_{n} \mathrm{Cl}_{6-n}\right]_{m}{ }^{28}$ Therefore, the synthesis of zircoaluminates can be described in the following equations:

$$
\begin{aligned}
& {\left[\mathrm{Al}_{2}(\mathrm{OH})_{n} \mathrm{Cl}_{6-n}\right]_{m}+a X\left(\mathrm{HOR}_{1} \mathrm{OH}\right) } \\
& \rightarrow {\left[\mathrm{Al}_{2}\left(\mathrm{OR}_{1} \mathrm{O}\right)_{a} \mathrm{Cl}_{b}(\mathrm{OH})_{c}\right]_{X} } \\
& {\left[\mathrm{Al}_{2}\left(\mathrm{OR}_{1} \mathrm{O}\right)_{a} \mathrm{Cl}_{b}(\mathrm{OH})_{c}\right]_{X}+Y\left[\mathrm{OC}\left(\mathrm{R}_{2}\right) \mathrm{O}\right] } \\
&+\mathrm{Z}\left[\mathrm{ZrCl}_{d}(\mathrm{OH})_{e}\right] \\
&\left.\rightarrow\left[\mathrm{Al}_{2}\left(\mathrm{OR}_{1} \mathrm{O}\right)_{a} \mathrm{Cl}_{b}(\mathrm{OH})_{c}\right]_{X}\left[\mathrm{OC}\left(\mathrm{R}_{2}\right) \mathrm{O}\right)\right]_{Y} \\
& {\left[\mathrm{ZrCl}_{d}(\mathrm{OH})_{e}\right]_{Z} }
\end{aligned}
$$

where $0<n<6$; $m$ is the polymerization degree of PAC; $a, b, c$, $d, e, X, Y$, and $Z$ are defined above. In this study, 1,2propanediol was used as $\mathrm{OR}_{1} \mathrm{O}$; adipic acid, methacrylic acid, lauric acid, and dodecyl dimethyl betaine were used as $\mathrm{OC}\left(\mathrm{R}_{2}\right) \mathrm{O}$, respectively. The resultant products were denoted as ZA-C, ZA-M, ZA-F, and ZA-Q, respectively. The detailed optimized conditions are as follows:

1. A $12 \mathrm{~g}$ sample of PAC was dissolved in $12 \mathrm{~mL}$ of deionized water in a continuously stirred flask $(V=250 \mathrm{~mL})$. After complete dissolution, $15 \mathrm{~mL}$ of methanol was added and the mixture was heated in a water bath. When the temperature of the mixture increased to $70{ }^{\circ} \mathrm{C}$, the required amount of 1,2 propanediol was added and the mixture was refluxed at $70{ }^{\circ} \mathrm{C}$ for $45 \mathrm{~min}$. Upon completion, some insoluble substances (about $0.5 \%$ of total product) were removed by centrifuge at $2000 \mathrm{rpm}$ in $10 \mathrm{~min}$. Subsequently, the active product was isolated by low vacuum solvent removal and dried in an oven at $105{ }^{\circ} \mathrm{C}$; this was the solid chelated PAC. The selected molar ratios of 1,2-propanediol to $\mathrm{Al}(\mathrm{P} / \mathrm{Al})$ were $0.25,0.5$, and 1 , respectively.

2. A chelated PAC solution was prepared by dissolving $10.3 \mathrm{~g}$ of solid chelated PAC with a $\mathrm{P} / \mathrm{Al}$ ratio of 0.5 (prepared above) in a $30 \mathrm{~mL}$ methanol. A $1.61 \mathrm{~g}$ sample of zirconium oxychloride powder was dissolved in $30 \mathrm{~mL}$ of isopropyl alcohol in a flask, $0.2 \mathrm{~mL}$ of hydrochloric acid was added, and the mixture was heated to $75{ }^{\circ} \mathrm{C}$ in a water bath. Subsequently, the prepared solution of chelated PAC was added gradually in $10 \mathrm{~min}$, and then the mixture was refluxed at $75{ }^{\circ} \mathrm{C}$ for $20 \mathrm{~min}$. After that, $5.69 \mathrm{~g}$ of adipic acid was added and refluxed at $75{ }^{\circ} \mathrm{C}$ for 40 min. Last, a very small amount of insoluble substances was removed by centrifuge at $2000 \mathrm{rpm}$ for $10 \mathrm{~min}$ and then filtrated on a Büchner funnel with filter paper. The resultant liquid was the final ZA-C product with lower alcohols (e.g., methanol, isopropyl) as solvent. Other products were synthesized under similar conditions and isolated the same way, while 1,2-propanediol was used as solvent in the preparation of ZA-Q. The yields for all zircoaluminate products were over $99 \%$.

In addition, the effects of the molar ratio of $\mathrm{P} / \mathrm{Al}$, the molar ratio of the chelated $\mathrm{PAC}$ to $\mathrm{Zr}(\mathrm{X} / \mathrm{Z})$, and the molar ratio of $\mathrm{OC}\left(\mathrm{R}_{2}\right) \mathrm{O}$ to the total metal $(\mathrm{Y} /(2 \mathrm{X}+\mathrm{Z}))$, on the properties of final products were studied and are discussed later in the paper.

2.3. Characterization of Zircoaluminates. With the use of deionized water, 2 wt \% aqueous solutions of the zircoaluminate products were prepared, and the $\mathrm{pH}$ value was measured with the use of a Sartorius basic $\mathrm{pH}$ meter PB-10 (Sartorius AG, Germany).

After complete digestion using nitric acid for removal of organic portions, the total aluminum content of zircoaluminate products was determined by a HACH-DR 2800 spectrophotometer (Hach Company, USA). In this method, the indicator reacts with aluminum in the sample to form a red-orange color, and the color intensity, which is measured at $522 \mathrm{~nm}$, is proportional to the aluminum concentration. Two or three replicates for each test were conducted and the average data were reported.

MALDI-TOF MS (matrix-assisted laser desorption/ionization time-of-flight mass spectrometry) spectra were acquired on an Autoflex III smartbeam MALDI-TOF MS instrument (Bruker, Germany) in the reflection mode. The matrix compound was DHB (2,5-dihydroxybenzoic acid; Bruker Daloinc Leipzig, Germany) dissolved in tetrahydrofuran. The zircoaluminate products were analyzed directly without separation.

For the FTIR and thermogravimetric (TGA) analyses, the samples were dried in an oven at $105{ }^{\circ} \mathrm{C}$ for $2 \mathrm{~h}$. FTIR spectra of samples were obtained from a Nicolet Nexus 470 FTIR spectrometer (Nicolet, USA). $\mathrm{KBr}$ pellets were prepared using the weight ratio of $\mathrm{KBr}$ (analytical reagent grade) to sample of 100:1. The spectra were collected in the range $4000-400 \mathrm{~cm}^{-1}$. TGA and DTG (differential thermogravimetry) curves were obtained using a Netzsch TG-209 thermogravimeter (Netzsch, 
Table 1. General Properties of Synthetic Zircoaluminate Products ${ }^{a}$

\begin{tabular}{|c|c|c|c|c|c|c|c|c|c|}
\hline $\begin{array}{l}\text { product } \\
\text { code }\end{array}$ & $\mathrm{R}_{2} \mathrm{COOH}$ & $\mathrm{P} / \mathrm{Al}$ & $\mathrm{X} / \mathrm{Z}$ & $\mathrm{Y} /(2 \mathrm{X}+\mathrm{Z})$ & $\begin{array}{l}\text { sp gravity } \\
(\mathrm{g} / \mathrm{mL})\end{array}$ & $\begin{array}{l}\text { solid content } \\
\text { (wt \%) }\end{array}$ & appearance $^{b}$ & $\mathrm{pH}^{b}$ & $\begin{array}{l}\text { Al content } \\
\text { (wt \%) }\end{array}$ \\
\hline ZA-C1 & adipic acid & 0.25 & 3 & 0.6 & 0.911 & 24.8 & light yellow, semitransparent & 3.61 & 7.63 \\
\hline ZA-C2 & adipic acid & 0.5 & 3 & 0.6 & 0.902 & 23.9 & light yellow, semitransparent & 3.67 & 7.23 \\
\hline ZA-C3 & adipic acid & 1 & 3 & 0.6 & 0.852 & 23.0 & light yellow, semitransparent & 3.70 & 6.54 \\
\hline ZA-C4 & adipic acid & 1 & 2 & 0.6 & 0.960 & 32.6 & light yellow, semitransparent & 3.69 & 6.21 \\
\hline ZA-C5 & adipic acid & 1 & 6 & 1.0 & 0.942 & 25.5 & light yellow, cloudy & 3.65 & 6.01 \\
\hline ZA-C6 & adipic acid & 1 & 6 & 0.6 & 0.918 & 25.9 & light yellow, semitransparent & 3.69 & 6.96 \\
\hline ZA-C7 & adipic acid & 1 & 6 & 0.2 & 0.910 & 28.6 & light yellow, clear & 3.72 & 8.12 \\
\hline ZA-M & methacrylic acid & 1 & 6 & 0.6 & 0.881 & 22.7 & light yellow, semitransparent & 3.89 & 9.58 \\
\hline $\mathrm{ZA}-\mathrm{F}$ & lauric acid & 1 & 6 & 0.6 & 0.877 & 22.4 & $\begin{array}{l}\text { two layers: clear for upper layer; white flocculent } \\
\text { precipitate for lower layer }\end{array}$ & 4.07 & 4.32 \\
\hline ZA-Q & $\begin{array}{l}\text { dodecyl dimethyl } \\
\text { betaine }\end{array}$ & 1 & 6 & 0.6 & 1.087 & 26.9 & $\begin{array}{l}\text { two layers: clear for upper layer; white flocculent } \\
\text { precipitate for lower layer }\end{array}$ & 4.26 & 3.17 \\
\hline
\end{tabular}

Germany) from room temperature to $900{ }^{\circ} \mathrm{C}$ and at a fixed heating rate of $10^{\circ} \mathrm{C} / \mathrm{min}$ under nitrogen flow.

\section{RESULTS AND DISCUSSION}

3.1. General Properties. For zircoaluminate products, the ratios of $\mathrm{P} / \mathrm{Al}, \mathrm{X} / \mathrm{Z}$, and $\mathrm{Y} /(2 \mathrm{X}+\mathrm{Z})$ can affect their properties. As reported by Cohen, ${ }^{1,2}$ the preferred ratios of $\mathrm{P} / \mathrm{Al}, \mathrm{X} / \mathrm{Z}$, and $\mathrm{Y} /(2 \mathrm{X}+\mathrm{Z})$ were $0.1-1.0,3-6$, and $0.1-1.0$, respectively. 1,2 Propanediol can impart the hydrolytic and hydroxylic stabilities of the final products. Accordingly, increasing the $\mathrm{P} / \mathrm{Al}$ ratio can improve the stability of the chelated PAC and, consequently, the stability of zircoaluminates. Aluminum has higher affinity to the substrate surface than zirconium does; thus, increasing the $\mathrm{X} / \mathrm{Z}$ ratio can have a positive effect on the reactivity of zircoaluminates, while decreasing the $\mathrm{X} / \mathrm{Z}$ ratio enhances the stability of the final products.

The general properties of zircoaluminate products with different functional groups are shown in Table 1 . As can be seen, the appearance of 2 wt \% aqueous solution of carboxylic zircoaluminates (ZA-C7) with a $\mathrm{Y} /(2 \mathrm{X}+\mathrm{Z})$ of 0.2 is clear, indicating good water solubility, while ZA-C5 with a $\mathrm{Y} /(2 \mathrm{X}+$ $\mathrm{Z})$ of 1.0 is cloudy (hazy), indicating poor water solubility. Therefore, increasing the $\mathrm{Y} /(2 \mathrm{X}+\mathrm{Z})$ ratio decreases the water solubility of zircoaluminates, which also means that the higher the ratio of $\mathrm{Y} /(2 \mathrm{X}+\mathrm{Z})$ the higher the organic compatibility of the final products.

The water solubilities of zircoaluminate depends on the organofunctional ligands as well. As presented in Table 1, ZA-F and ZA-Q samples with long carbon chains are water insoluble, and their $2 \mathrm{wt} \%$ aqueous solutions have two layers: the upper layer is clear and colorless; the lower layer is a white flocculent precipitate. In general, the products with carboxyl and methacrylic groups show better water solubilities. In addition, the solid content can affect the solubilities of zircoaluminates in a given solvent. For example, some precipitate will occur when the solid content of the sample ZA-C3 increases to 4 wt \% in water. Please note that when the solid content of the synthesized zircoaluminate is over $40 \mathrm{wt} \%$, the inorganic polymerization of the product may take place, thus causing it to lose its activity. The solid contents of the commercial zircoaluminate products are also in the range 20-40 wt \% (such as MANCHEM zircoaluminates ${ }^{29}$ ).

3.2. FTIR. Figure 1 displays the FTIR spectra of PAC (Figure 1a) and the chelated PAC prepared with $\mathrm{P} / \mathrm{Al}$ ratios of 0.25 (Figure 1b), 0.5 (Figure 1c), and 1.0 (Figure 1d). For PAC (Figure 1a), the broad band at $3430 \mathrm{~cm}^{-1}$ is associated with the

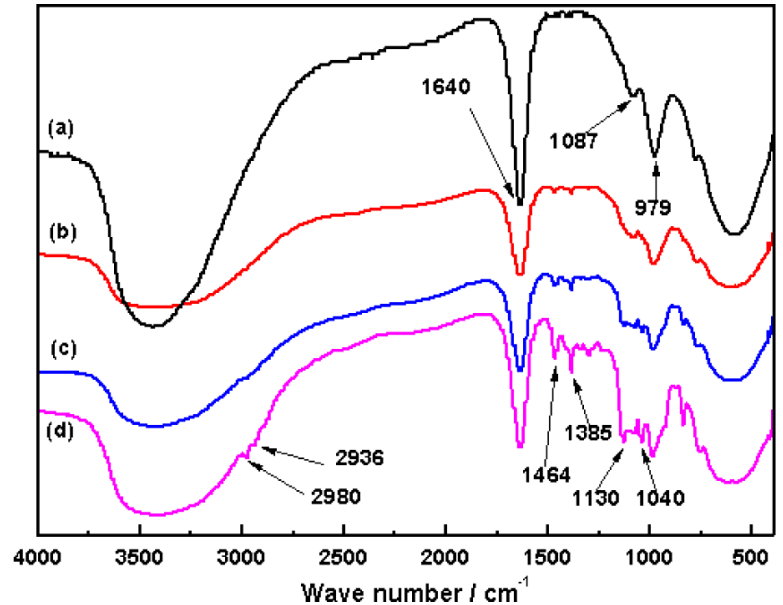

Figure 1. FTIR spectra of (a) PAC and chelated PAC with different molar ratios of 1,2-propanediol to $\mathrm{Al}$ of (b) 0.25 , (c) 0.5 , and (d) 1.0.

hydroxyl stretching vibration ${ }^{30}$ and the band at $1640 \mathrm{~cm}^{-1}$ is assigned to the $\mathrm{OH}$ bending vibration of water molecules in the $\mathrm{Al}_{13}$ structure. ${ }^{31,32}$ The $1087 \mathrm{~cm}^{-1}$ band is related to $\mathrm{Al}-\mathrm{O}-\mathrm{H}$ bending of the bridged hydroxyl anions, and similar results at $1085 \mathrm{~cm}^{-1}$ were obtained for the $\mathrm{Al}-\mathrm{O}-\mathrm{H}$ absorption band. ${ }^{32}$ The band at $979 \mathrm{~cm}^{-1}$ is assigned to the $\mathrm{Al}-\mathrm{OH}$ deformation bending, which is in agreement with $980 \mathrm{~cm}^{-1}$ reported by Kloprogge et al. ${ }^{32}$ Furthermore, the band at $639 \mathrm{~cm}^{-1}$ is assigned to the symmetric stretching mode of $\mathrm{Al}-\mathrm{O}$ bond of the central $\mathrm{AlO}_{4}{ }^{-}$in the $\mathrm{Al}_{13}$ units.

For the chelated PAC (Figure $1 \mathrm{~b}-\mathrm{d}$ ), the bands at 2980 and $2936 \mathrm{~cm}^{-1}$ are ascribed to the asymmetric stretching vibration of methyl and methylene groups, respectively. ${ }^{34}$ The peak at $1464 \mathrm{~cm}^{-1}$ is attributed to the scissoring vibration of methylene or the symmetric deformation of methyl group. ${ }^{35}$ The peak at $1385 \mathrm{~cm}^{-1}$ is due to the symmetric bending vibration of $-\mathrm{CH}_{3}$. The peaks at 1130 and $1040 \mathrm{~cm}^{-1}$ are assigned to the stretching mode of $\mathrm{C}-\mathrm{O}$ from secondary alcohol and primary alcohol, respectively, while the peak at $\sim 840 \mathrm{~cm}^{-1}$ is due to the $\mathrm{CH}$ bending vibration. In addition, the intensities of these peaks were enhanced as the $\mathrm{P} / \mathrm{Al}$ ratio increased (Figure 1). These results supported the conclusion that 1,2-propanediol was chelated to PAC for these samples.

FTIR spectra of zircoaluminates with carboxyl (sample ZAC6), methacrylic (sample ZA-M), dodecyl (sample ZA-F), and quaternary ammonium groups (sample ZA-Q) are given in 
Figure 2. For sample ZA-C6, it can be seen from Figure 2 that there are multiple bands between 1627 and $1580 \mathrm{~cm}^{-1}$, which

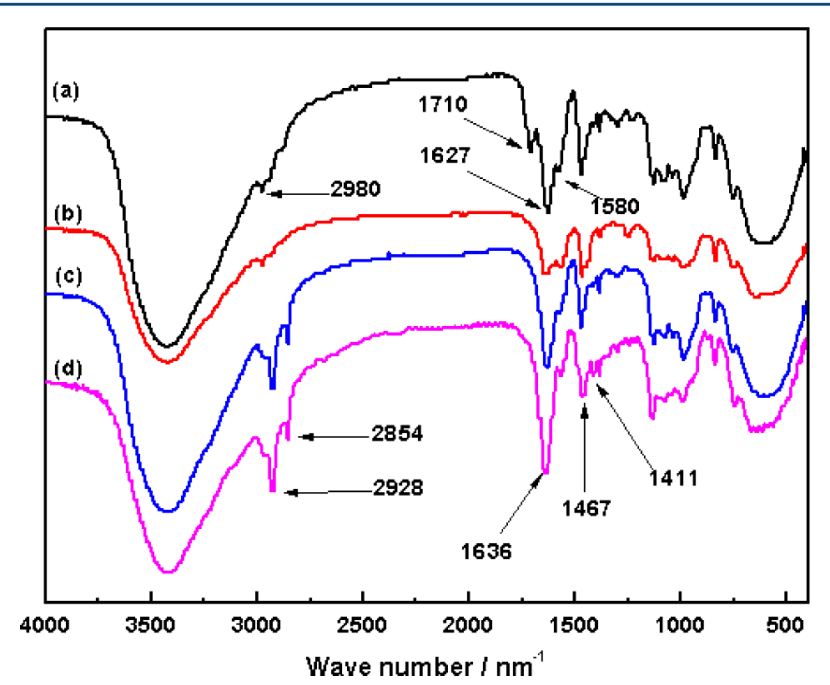

Figure 2. FTIR spectra of zircoaluminate coupling agents with different functional groups. (a) Sample ZA-C6, (b) sample ZA-M, (c) sample ZA-F, and (d) sample ZA-Q.

are due to the asymmetric stretching vibration of carboxylate and are in agreement with the characteristics of zircoaluminates. ${ }^{21,23}$ Also, these multiple bands are overlapped by those of hydroxyl $\left(1640 \mathrm{~cm}^{-1}\right)$ from the adsorbed water molecules. In free carboxylic ion, the asymmetric stretches of $\mathrm{COO}^{-}\left(\nu_{\mathrm{as}}\right)$ and symmetric stretches of $\mathrm{COO}^{-}\left(\nu_{\mathrm{s}}\right)$ are at approximately 1560 and $1400 \mathrm{~cm}^{-1}$, respectively. ${ }^{36}$ If dissociated, the carboxylate has a multielectronic $\pi$ bond $\left(\pi_{4 / 3}\right)$, and it can coordinate with a metal ion, forming the structures as ${ }^{37}$<smiles>[M]OC([R])=O</smiles>

I( Unidentate)<smiles>[R]C1OO1</smiles>

II ( Chelating)<smiles>[M]OC([R])O[M]</smiles>

III( Bridging)
In the unidentate structure (I), the peak of $\nu_{\mathrm{as}}(\mathrm{COO})$ is higher than that of free carboxylic ion and the peak of $\nu_{\mathrm{s}}(\mathrm{COO})$ is lower than that of free carboxylic ion, whereas the opposite was observed in the bidentate structure (II). ${ }^{37}$ Deacon and Philips $^{38}$ found that the structure of carboxylate coordination could be predicted by $\Delta \nu\left(\nu_{\mathrm{as}}-\nu_{\mathrm{s}}\right):$ if $\Delta \nu\left(\nu_{\mathrm{as}}-\nu_{\mathrm{s}}\right)$ is lower than that of free $\mathrm{COO}^{-}$, the coordination is bidentate; if $\Delta \nu\left(\nu_{\mathrm{as}}-\nu_{\mathrm{s}}\right)$ is higher than that of free $\mathrm{COO}^{-}$, the coordination can be assigned as unidentate. The bridging structure (III) usually has a higher $\Delta \nu$, ranging from 120 to $160 \mathrm{~cm}^{-1} \cdot{ }^{37}$ In sample ZA$\mathrm{C} 6, \nu_{\text {as }}(\mathrm{COO})$ was at $1627-1580 \mathrm{~cm}^{-1}$, while $\nu_{s}(\mathrm{COO})$ was at $1467 \mathrm{~cm}^{-1}$, which is overlapped by the deformation of $-\mathrm{CH}_{2}-$ or $-\mathrm{CH}_{3}$ at $1464 \mathrm{~cm}^{-1}$. On the basis of these results, it can be concluded that the structure of carboxylate coordination in sample ZA-C6 is in the "bridging" form, with $\Delta \nu$ of 113-160 $\mathrm{cm}^{-1}$. The peaks at 1627 and $1580 \mathrm{~cm}^{-1}$ are attributed to COOAl and COOZr, respectively, which are compared to 1610 and $1585 \mathrm{~cm}^{-1}$ reported by Cohen. ${ }^{1}$ Similar results were also reported by Freischmidt and Michell. ${ }^{39}$ In addition, the peak at $1710 \mathrm{~cm}^{-1}$ (Figure 2a) is indicative of $\mathrm{C}=\mathrm{O}$ stretching in the $\mathrm{COOH}$ form. ${ }^{21,35}$ This is because there are two carboxyl groups in adipic acid: one is in the "bridging" structure; the other remains free (as the functional group of zircoaluminate coupling agent). On the basis of these results and previous reports, ${ }^{21,23}$ the partial structure of sample ZA-C6 is shown in Figure 3.

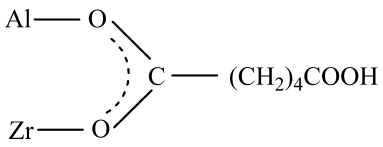

Figure 3. Partial structure of zircoaluminate (sample ZA-C6; adapted from Freischmidt and Michell $^{39}$ as well as Chen et al. ${ }^{11}$ ).

Compared to the results for sample ZA-C6 (Figure 2a), similar bands between 1636 and $1567 \mathrm{~cm}^{-1}$ for samples ZA-M, ZA-F, and ZA-Q are also shown in curves, b, c, and d, respectively, of Figure 2. In Figure $2 b$, these multiple bands are overlapped by $\mathrm{C}=\mathrm{C}$ stretching vibration $\left(1645 \mathrm{~cm}^{-1}\right)$ from methacrylic acid. ${ }^{35}$ The bands at 2928 and $2854 \mathrm{~cm}^{-1}$ are assigned to the asymmetric and symmetric stretching vibrations of $\mathrm{CH}_{2}$, respectively. They are derived from lauric acid for sample ZA-F and dodecyl dimethyl betaine for sample ZA-Q. In Figure $2 \mathrm{~d}$, the peak at $1411 \mathrm{~cm}^{-1}$ is assigned to $\mathrm{C}-\mathrm{N}$ stretching vibrations. ${ }^{35}$

3.3. Molecular Weight Distribution. In this study, MALDI-TOF MS was employed to determine the molecular weight distribution of the products. The results of $M_{\mathrm{n}}$ (numberaverage molecular weight), $M_{\mathrm{w}}$ (weight-average molecular weight), and PI (polydispersity index) of the synthetic zircoaluminates with different functional groups are given in Table 2. As can be seen, the $M_{\mathrm{n}}$ and $M_{\mathrm{w}}$ of sample ZA-C6 are

Table 2. Estimation of Molecular Weight Distribution of Zircoaluminates with Different Functional Groups

\begin{tabular}{clccc} 
product code & functional group & $M_{\mathrm{n}}(\mathrm{g} / \mathrm{mol})$ & $M_{\mathrm{w}}(\mathrm{g} / \mathrm{mol})$ & PI \\
ZA-C6 & carboxyl & 2125 & 2295 & 1.08 \\
ZA-M & methacrylic & 1495 & 1755 & 1.17 \\
ZA-F & dodecyl & 2035 & 2514 & 1.24 \\
ZA-Q & quaternary ammonium & 1900 & 2494 & 1.31 \\
\hline
\end{tabular}

2125 and $2295 \mathrm{~g} / \mathrm{mol}$, respectively, and it has a narrow polydispersity of 1.08. Sample ZA-M has the lowest $M_{\mathrm{n}}$ (1495 $\mathrm{g} / \mathrm{mol})$ and $M_{\mathrm{w}}(1755 \mathrm{~g} / \mathrm{mol})$. This may be due to the small molecule of methacrylic acid used as the organofunctional ligand. However, samples ZA-F and ZA-Q have polydispersity values of 1.24 and 1.31 , respectively. It is noted that caution should be taken when evaluating the molecular weight results from MALDI-TOF MS for polymers with PI > 1.2, because, in many cases, polymers with a PI larger than 1.2 show an underestimation of the molecular weight distribution toward the high molar mass range. ${ }^{40}$ The relatively larger polydispersities of ZA-F and ZA-Q indicate that their molecular distributions are inhomogeneous, which is possibly due to the relatively larger molecules of dodecyl and quaternary ammonium used. Therefore, more accurate estimations for the samples ZA-F and ZA-Q may be needed in future investigation (e.g., test after appropriate separation/fractionation).

Although zircoaluminate coupling agent is usually presented by the empirical formula $\left[\mathrm{Al}_{2}\left(\mathrm{OR}_{1} \mathrm{O}\right)_{a} \mathrm{Cl}_{b}(\mathrm{OH})_{c}\right]_{X}\left[\mathrm{OC}\left(\mathrm{R}_{2}\right) \mathrm{O}\right]_{Y}$ $\left[\mathrm{ZrCl}_{d}(\mathrm{OH})_{e}\right]_{\mathrm{Z}}$, its molecular structure is complicated, which depends on the raw materials used (such as PAC, containing various $\mathrm{Al}$ species ${ }^{26,27,33}$ ), the molar ratio of the reactants, and the selected route and conditions of synthesis. Therefore, it is not easy to determine the mass spectra of zircoaluminates. The 
MALDI-TOF mass spectrum of sample ZA-C6 is shown in Figure 4. It is seen that its molecular weight ranged from about

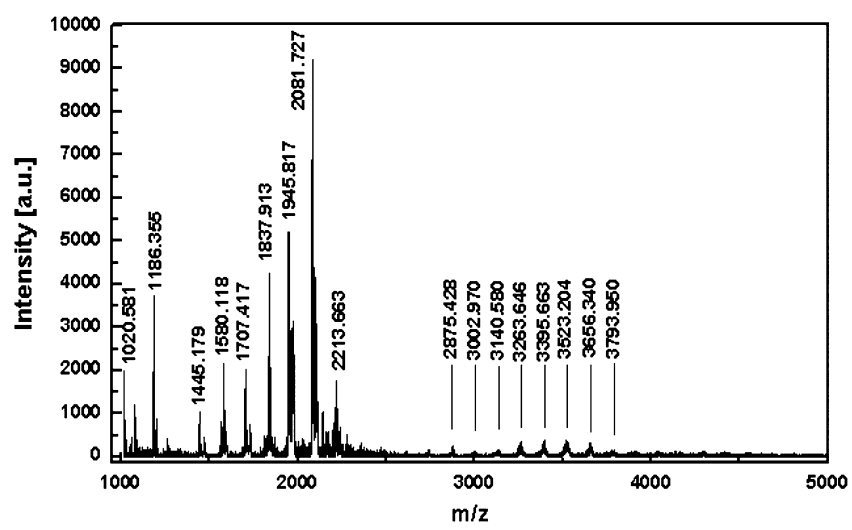

Figure 4. MALDI-TOF mass spectrum of zircoaluminates (sample ZA-C6).

1000 to $4000 \mathrm{~g} / \mathrm{mol}$. The mass differences between the adjacent peaks indicate the complex nature of the molecular structure. The complex structure of PAC may also result in the difference of each structural unit of zircoaluminates. However, as presented in Figure 4, the mass increment between two adjacent peaks is about $130 \mathrm{~g} / \mathrm{mol}$, which is most likely related to the repeat unit of the chelated aluminum moiety in zircoaluminates, as every two $\mathrm{Al}$ atoms (mass $27 \cdot 2=54$ ) are chelated by one molecule of 1,2-propanediol $\left(\mathrm{C}_{3} \mathrm{H}_{8} \mathrm{O}_{2}\right.$, mass 76) during the preparation of the chelated PAC. In addition, as indicated by Cohen, ${ }^{1}$ when the aluminum moiety or the zirconium moiety forms its terminus, one of the hydroxyl groups or chlorine atoms may be replaced by an alkoxyl group having one to six carbon atoms.

3.4. Thermal Decomposition Behavior. The thermal decomposition behavior of different zircoaluminate products is shown in Figures 5-7. It is seen that, in the temperature range $25-900{ }^{\circ} \mathrm{C}$, the weight loss of zircoaluminates occurs in four distinct stages. The temperature range of each stage varies with different products. In the first stage of $\leq 170{ }^{\circ} \mathrm{C}$, the weight loss is related to the removal of adsorbed water molecules. In the second stage of $170-350{ }^{\circ} \mathrm{C}$, the weight loss may be associated with the dehydroxylation of inorganic parts in zircoalumi- nates. ${ }^{41,42}$ The third decomposition stage of $350-500{ }^{\circ} \mathrm{C}$ is attributed to the decomposition of zircoaluminates and the combustion of organic portions; it was reported that the decomposition point of zircoaluminates is above $300{ }^{\circ} \mathrm{C} .{ }^{1,21}$ Based on the weight loss in the first $\left(W_{1}\right)$ and third stages $\left(W_{3}\right)$, the weight percentage of inorganic portion $\left(W_{\text {inorg }}\right)$ in zircoaluminates can be calculated as

$$
W_{\text {inorg }}=\frac{1-W_{1}-W_{3}}{1-W_{1}} \cdot 100 \%
$$

In the last stage $\left(\geq 500{ }^{\circ} \mathrm{C}\right)$, the weight loss is due to the slow decomposition of residual inorganic portions.

Shown in Figure 5 are the effects of the $\mathrm{P} / \mathrm{Al}$ ratio on the thermal decomposition behaviors of zircoaluminates. As can be seen from the TG curves (Figure 5a), the total weight losses of sample ZA-C1, ZA-C2, and ZA-C3 are 59.36, 63.32, and $63.83 \%$, respectively. The increasing of total weight loss is due to the increase of the $\mathrm{P} / \mathrm{Al}$ ratio, which is expected. The weight losses in the third stage of ZA-C1, ZA-C2, and ZA-C3 are $11.95,12.59$, and $13.18 \%$, respectively, which are close and expected because the organic contents in these samples are similar $(16.06,17.32$, and $18.05 \%$, respectively) and the weight losses in these temperature ranges are related to the decomposition of zircoaluminates and the combustion of organic portions. As shown in the DTG curves (Figure 5b), when the used $\mathrm{P} / \mathrm{Al}$ increases from 0.25 to 1.0 , the peaks tend to shift to a higher temperature in each decomposition stage, and the decomposition temperatures in the third stage of samples ZA-C1, ZA-C2, and ZA-C3 are 342, 357, and $369^{\circ} \mathrm{C}$, respectively. These results indicate that increasing the $\mathrm{P} / \mathrm{Al}$ ratio can increase the decomposition temperatures of zircoaluminates, leading to improved thermal stabilities of zircoaluminates.

At a given ratio of $\mathrm{P} / \mathrm{Al}$ of 1.0 , the effects of $\mathrm{X} / \mathrm{Z}$ ratio on the thermal decomposition behavior of zircoaluminates are shown in Figure 6a (TG) and Figure $6 \mathrm{~b}$ (DTG). The $\mathrm{X} / \mathrm{Z}$ ratio is 6 for sample ZA-C6 or 2 for sample ZA-C4. The ratio of $\mathrm{Y} /(2 \mathrm{X}+\mathrm{Z})$ is 0.6 (Table 1). As presented in Figure $6 \mathrm{~b}$, decreasing the $\mathrm{X} / \mathrm{Z}$ ratio reduces the peak area in the first decomposition stage (due to the loss of adsorbed water), and the weight losses of samples ZA-C6 and ZA-C4 are 26.42 and $25.03 \%$, respectively. The weight loss in the second stage is attributed to the removal of hydroxyl groups, which are mainly derived from the
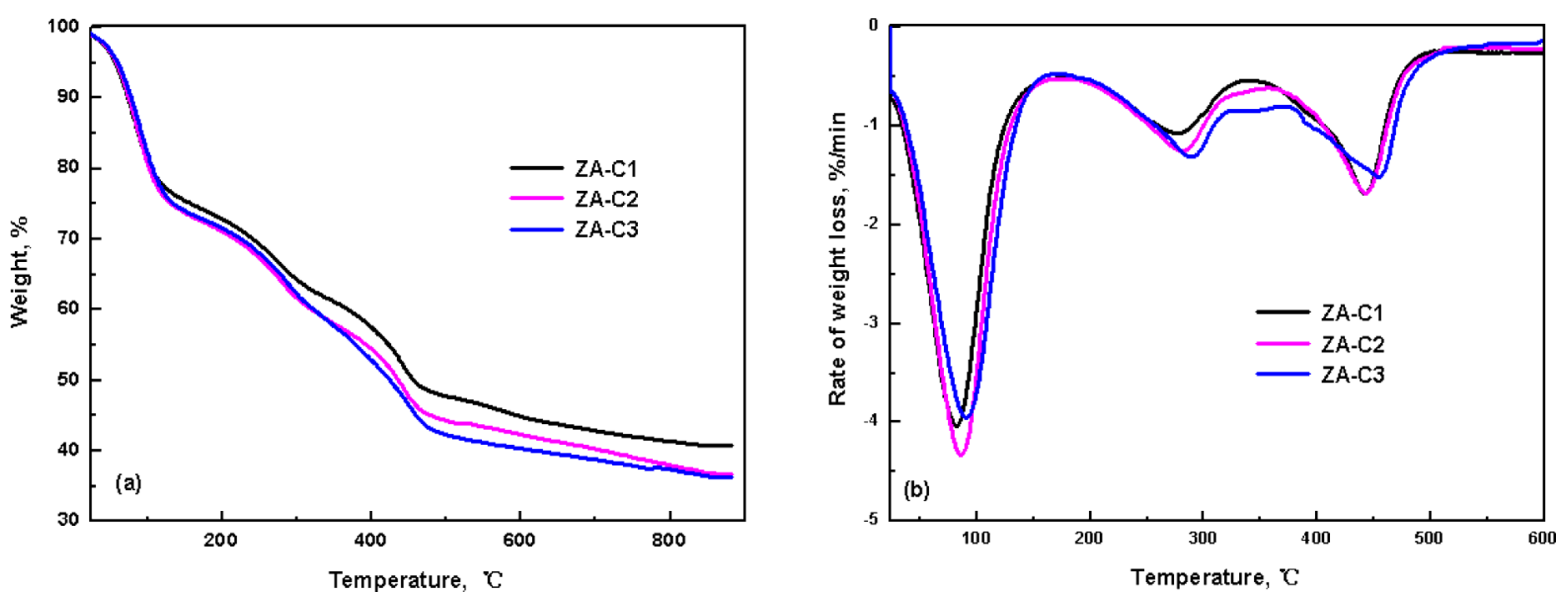

Figure 5. Effect of $\mathrm{P} / \mathrm{Al}$ ratio on thermal decomposition behavior of zircoaluminates. (a) TG; (b) DTG. P/Al ratio: 0.25 for sample ZA-C1, 0.5 for sample ZA-C2, and 1.0 for sample ZA-C3. 

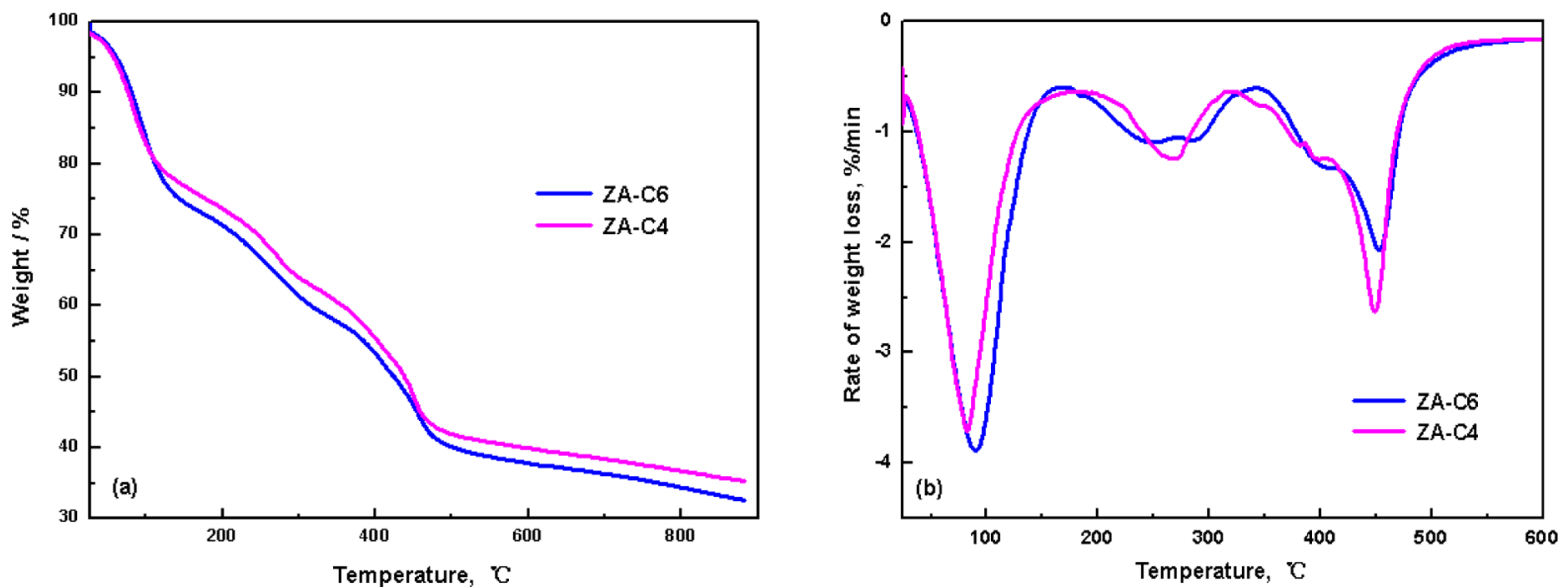

Figure 6. Effect of $X / Z$ ratio on the thermal decomposition behavior of zircoaluminates. (a) TG; (b) DTG. X/Z ratio: 6 for sample ZA-C6; 2 for sample ZA-C4.
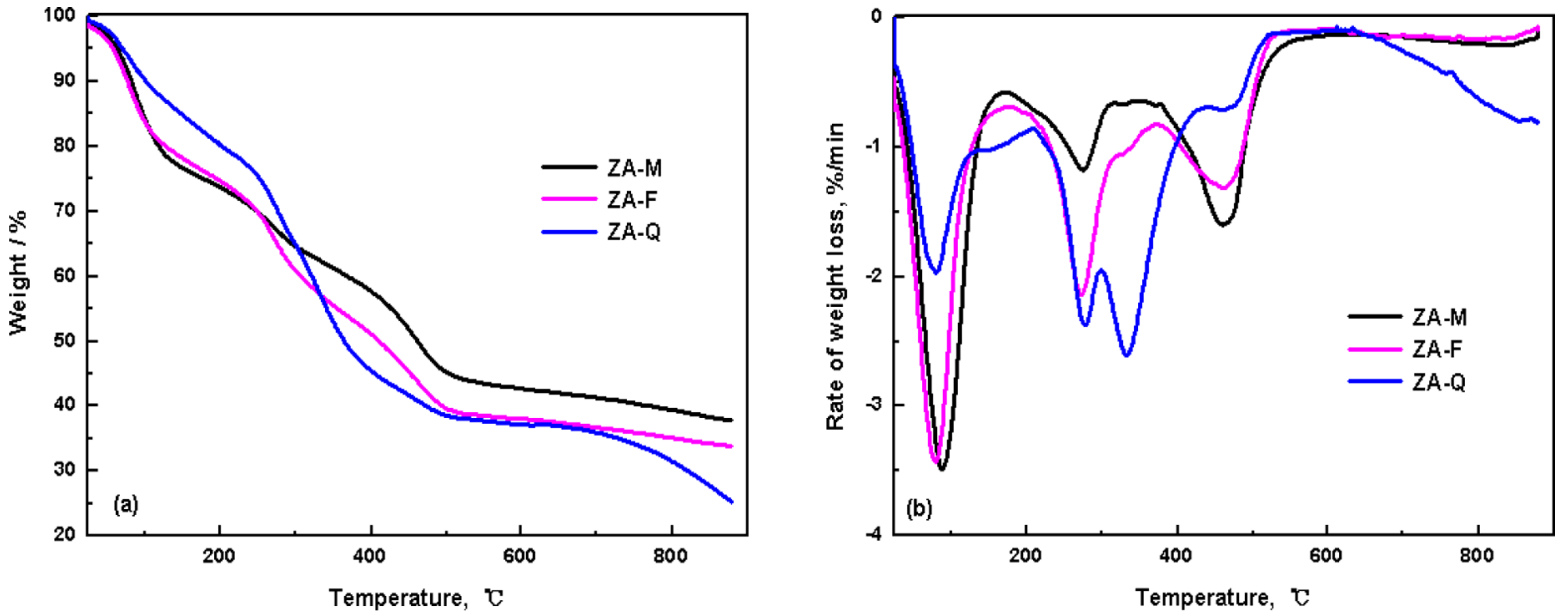

Figure 7. Effect of different organofunctional ligands on thermal decomposition behavior of zircoaluminates. (a) TG; (b) DTG.

inorganic portions of zircoaluminates. ${ }^{41}$ According to the TG curves in Figure 6a, the weight loss of sample ZA-C6 in the second stage is $15.51 \%$, which is higher than that of sample ZAC4 $(12.34 \%)$. This is in agreement with the fact that the inorganic portion of sample ZA-C6 (73.2\%) is higher than that of sample ZA-C4 (70.4\%). In addition, it can be seen from Figure $6 \mathrm{a}$ that the weight losses in the third decomposition stage of samples ZA-C6 and ZA-C4 are 19.75 and $22.20 \%$, respectively. This is because decreasing the $\mathrm{X} / \mathrm{Z}$ ratio leads to the increase of organic portion in zircoaluminates at a given $X$ and $\mathrm{Y} /(2 \mathrm{X}+\mathrm{Z})$. Figure $6 \mathrm{~b}$ also shows that the decomposition temperature of sample ZA-C6 $\left(345^{\circ} \mathrm{C}\right)$ is higher than that of sample ZA-C4 $\left(320^{\circ} \mathrm{C}\right)$. These results suggest that, at a given ratio of $\mathrm{P} / \mathrm{Al}$ and $\mathrm{Y} /(2 \mathrm{X}+\mathrm{Z})$, decreasing the $\mathrm{X} / \mathrm{Z}$ ratio can lower the decomposition temperature of zircoaluminates. That is, to improve the thermal stability of final zircoaluminates, the amount of the chelated PAC may be appropriately increased.

Figure 7a (TG) and Figure $7 \mathrm{~b}$ (DTG) illustrate the effects of different organofunctional ligands on the thermal decomposition behavior of zircoaluminates. For samples ZA-M, ZA-F, and $\mathrm{ZA}-\mathrm{Q}$, the $\mathrm{P} / \mathrm{Al}$ ratio is $1.0, \mathrm{X} / \mathrm{Z}$ is 6 , and $\mathrm{Y} /(2 \mathrm{X}+\mathrm{Z})$ is 0.6 (Table 1). As can be seen from Figure 7 , the decomposition in each stage varies with different organofunctional ligands. For instance, the weight loss of sample ZA-Q in the first stage is $20.47 \%$, which is significantly lower than that of other products.
This is because of the long carbon chain from dodecyl dimethyl betaine, leading to its lower hydrophilicity or higher hydrophobicity. Figure 7 also shows that, unlike other products, there is an obvious weight loss of sample ZA-Q in the fourth decomposition stage. In addition, samples ZA-M and ZA-F have higher decomposition temperature (354 and $374{ }^{\circ} \mathrm{C}$, respectively), while sample $\mathrm{ZA}-\mathrm{Q}$ has the lowest decomposition temperature $\left(302{ }^{\circ} \mathrm{C}\right)$. It can be concluded that the organofunctional ligand used in the synthesis is critical for the thermal stability of zircoaluminates.

\section{CONCLUSIONS}

A series of zircoaluminates with different functional groups were synthesized, and some important properties, including the molecular weight distribution and thermal decomposition behavior of the synthetic products, were characterized. FTIR results showed that the multiple bands at $1636-1567 \mathrm{~cm}^{-1}$ are the characteristics of zircoaluminates, while the spectra differences of the different products are mainly due to the specific organofunctional ligands used in the synthesis. The complex structure of zircoaluminates, to a large extent, depends on the raw material used. On the basis of the MALDI-TOF MS results, the number-average molecular weight and weightaverage molecular weight of carboxyl functional zircoaluminate (sample ZA-C6) are 2125 and $2295 \mathrm{~g} / \mathrm{mol}$, respectively, and it 
has a narrow polydispersity of 1.08 , while the dodecyl functional zircoaluminate (sample ZA-F) and quaternary ammonium functional zircoaluminate (sample ZA-Q) have polydispersity values of 1.24 and 1.31 , respectively.

The molar ratios of 1,2-propanediol to $\mathrm{Al}(\mathrm{P} / \mathrm{Al})$, the chelated $\mathrm{PAC}$ to $\mathrm{Zr}(\mathrm{X} / \mathrm{Z})$, and the organofunctional ligand to the total metals $(\mathrm{Y} /(2 \mathrm{X}+\mathrm{Z}))$ can affect the properties of the final products. Increasing the ratio of $\mathrm{Y} /(2 \mathrm{X}+\mathrm{Z})$ can increase the organic compatibility of products, but lower the water solubility. The best thermal stability can be obtained when the ratios of $\mathrm{P} / \mathrm{Al}$ and $\mathrm{X} / \mathrm{Z}$ were optimized. In addition, the organofunctional ligands can affect the thermal stability of zircoaluminates as well. Therefore, the resultant products can be tailored by better controlling these key parameters during synthesis according to their final usage, and better understanding of the key properties of zircoaluminate coupling agents is very crucial for further development of new zircoaluminate products and better utilization of zircoaluminates.

\section{AUTHOR INFORMATION}

\section{Corresponding Author}

*E-mail: libin@qibebt.ac.cn. Tel.: +86-(532)-80662725. Fax: +86-(532)-80662724.

\section{Notes}

The authors declare no competing financial interest.

\section{ACKNOWLEDGMENTS}

The financial support for this project was from the Innovation Program, the Ministry of Education of China (IRT0552).

\section{ABBREVIATION}

$\mathrm{PAC}=$ polyaluminum chloride

\section{REFERENCES}

(1) Cohen, L. B. Aluminum zirconium metallo-organic complexes useful as coupling agents. U.S. Patent 4,539,048, Sept 3, 1985.

(2) Cohen, L. B. Multifunctional amino zirconium aluminum metallo organic complexes useful as adhesion promoter. U.S. Patent 4,764,632, Aug 16, 1988

(3) Cohen, L. B. Zircoaluminates strengthen premium ranges of chemical coupling agents. Plast. Eng. 1983, 39, 29-32.

(4) Cohen, L. B. Zircoaluminate adhesion promoters. J. Adhes. Sci. Technol. 1991, 5, 439-448.

(5) Marrion, A. R. The Chemistry and Physics of Coatings, 2nd ed.; Royal Society of Chemistry, Tyne and Wear, U.K., 2004.

(6) Chou, S.; Chen, H.-C.; Lee, K.-S. Effects of the organometallic coupling agents on adhesion of the carbon fiber-BMI composites. J. Appl. Polym. Sci. 1992, 45, 683-694.

(7) Yuan, S. C. Primers containing zircoaluminate coupling agents for improved adhesion. U.S. Patent 5,468,791, Nov 21, 1995.

(8) Rosenstiel, S. F.; Van Putten, M. C., Jr.; Culbertson, B. M.; Johnson, M. A. Titanates and zircoaluminates as coupling agents for dental cements. Int. J. Prosthodontics 1993, 6, 298-302.

(9) Chou, S.; Lin, L.-S.; Yeh, J.-T. Effect of surface treatment of glass fibres on adhesion to phenolic resin. Polym. Polym. Compos. 1999, 7, $21-31$.

(10) Melzer, J. I.; Gunagan, B. P. Process for enhanced drainage of residual aqueous rinse on the external surface of plastic parts. U.S. Patent 5,314,546, May 24, 1994.

(11) Chen, J.-Z.; Zhao, Y.-N. Preparation method of cation aluminium zirconium metal-organic complex coupling agent. Chinese Patent 1763050, April 26, 2006.
(12) Chen, J.-Z.; Feng, L.-X.; Zhao, Y.-N. Retention effect of cationic aluminum zirconium coupling agents. China Pulp Pap. 2006, 25 (5), $16-19$.

(13) Furman, B. R.; Wellinghoff, S. T.; Rawls, H. R.; Dixon, H.; Norling, B. K. Mechanically strong and transparent or translucent composites made using zirconium oxide nanoparticles U.S. Patent 6,194,481, Feb 27, 2001.

(14) Tang, Y.-J.; Li, Y.-M.; Song, J.; Pan, Z.-D. Surface modification of nanosized $\mathrm{CaCO}_{3}$ for paper coating. Chin. J. Inorg. Chem. 2006, 22, 2018-2024.

(15) Tang, Y.-J.; Li, Y.-M.; Hu, D.-W. Modification, surface structure and rheological behavior of nanosized $\mathrm{CaCO}_{3}$. Acta Chim. Sin. 2007, 65 (20), 2291-2298.

(16) Tang, Y.-J.; Li, Y.-M.; Xue, G.-X.; Zhang, X. M.; Zhao, Y. Study on surface modification of nanosized $\mathrm{CaCO}_{3}$ and its application in improving the properties of pigment coated paper. Second International Papermaking and Environment Conference, Proceedings, Tianjin, China, May 14-16, 2008; China Light Industry Press: Beijing, 2008; pp 868871 .

(17) Shen, J.; Song, Z. Q.; Qian, X. R.; Ni, Y. H. Carbohydrate-based fillers and pigments for papermaking: A review. Carbohydr. Polym. 2011, 85, 17-21.

(18) Tang, Y.-J.; Li, Y.-M.; Xue, G.-X. Stability of modified nanosized $\mathrm{CaCO}_{3}$ dispersion system in aqueous medium and extended DLVO theory. Trans. China Pulp Pap. 2010, 25, 54-58.

(19) Li, B.; Li, Y.-M.; Yang, W.-L. Modification of nanometer titanium dioxide and its application as part of novel retention systems. Second International Papermaking and Environment Conference, Proceedings, Tianjin, China, May 14-16, 2008; China Light Industry Press: Beijing, 2008; pp 778-781.

(20) Li, B.; Li, Y.-M.; Kang, Y.-Z.; Lei, L.-R.; Wan, X.-F. Preparation of aluminum-zirconium coupling agent. Chinese Patent CN 101407644, April 15, 2009.

(21) Li, B.; Li, Y.-M.; Yang, W.-L. Synthesis and application of zircoaluminate coupling agent as surface modifier of nano-sized titanium dioxide. J. South China Univ. Technol., Nat. Sci. 2009, 37, 712.

(22) Li, B.; Li, Y.-M.; Lu, R.-J. Effect of modified nanoTiO ${ }_{2}$ on properties of coating and coated paper. CIESC J. 2010, 61 (1), 228234.

(23) Guo, B.; Xu, J.; Tang, H.; Cao, X.; Li, B.-G.; Guo, F.; Gao, Y. Surface modification of long afterglow phosphors by different saturated fatty acid based $\mathrm{Al}-\mathrm{Zr}$ coupling agent. Paint Coat. Ind. 2011, 41, 9-13.

(24) Li, B.; Li, Y.-M.; Yang, W.-L.; Lei, L.-R. Preparation of anionic aluminum-zirconium coupling agent. Chinese Patent CN 101407643, April 15, 2009.

(25) Fatehi, P.; Ates, S.; Ward, J. E.; Ni, Y. H.; Xiao, H. N. Impact of cationic polyvinyl alcohol on properties of papers made from two different pulps. Appita J. 2009, 62 (4), 303-307.

(26) Rowsell, J.; Nazar, L. F. Speciation and thermal transformation in alumina sols: structure of the polyhydroxyoxoaluminum cluster $\left[\mathrm{Al}_{30} \mathrm{O}_{8}(\mathrm{OH})_{56}\left(\mathrm{H}_{2} \mathrm{O}\right)_{26}\right]^{18+}$ and its $\delta$-Keggin Moieté. J. Am. Chem. Soc. 2000, 122, 3777-3778.

(27) Tzoupanos, N. D.; Zouboulis, A. I.; Tsoleridis, C. A. A systematic study for the characterization of a novel coagulant (ployaluminium silicate chloride). Colloids Surf., A 2009, 342, 30-39.

(28) Zouboulis, A. I.; Tzoupanos, N. Alternative cost-effective preparation method of poly-aluminium chloride (PAC) coagulant agent: characterization and comparative application for water/ wastewater treatment. Desalination 2010, 250, 339-344.

(29) http://www.manchem.com/Adhesion-Promoters/mechanism. html.

(30) Shen, J.; Song, Z.; Qian, X.; Ni, Y. A review on use of fillers in cellulosic paper for functional applications. Ind. Eng. Chem. Res. 2011, 50 (2), 661-666.

(31) Kloprogge, J. T.; Frost, R. L. Raman and infrared spectroscopic investigation of the neutralization of aluminium in the presence of 
monomeric orthosilicic acid. Spectrochim. Acta, Part A 1999, 55, 13591369.

(32) Kloprogge, J. T.; Geus, J. W.; Jansen, J. B. H.; Seykens, D. Thermal stability of basic aluminum sulfate. Thermochim. Acta 1992, 209, 265-276.

(33) Ng, M.; Liana, A. E.; Liu, S.; Lim, M.; Chow, C. W. K.; Wang, D.; Drikas, M.; Amal, R. Preparation and characterization of newpolyaluminum chloride-chitosan composite coagulant. Water Res. 2012, 46, 4614-4620.

(34) Liu, Z.; Fatehi, P.; Jahan, M. S.; Ni, Y. H. Separation of lignocellulosic materials by combined process of pre-hydrolysis and ethanol extraction. Bioresour. Technol. 2011, 102, 1264-1269.

(35) Larkin, P. Infrared and Raman Spectroscopy; Principles and Spectral Interpretation; Elsevier; New York, 2011.

(36) Petroski, J.; El-Sayed, M. A. FTIR study of the adsorption of capping material to different platinum nanoparticle shapes. J. Phys. Chem. A 2003, 107, 8371-8375.

(37) Nakamoto, K. Infrared and Raman Spectra of Inorganic and Coordination Compounds, Part B, 6th ed.; John Wiley \& Sons, Inc.: Hoboken, NJ, 2009.

(38) Deacon, G. B.; Philips, R. J. Relationships between the carbonoxygen stretching frequencies of carboxylato complexes and the type of carboxylate coordination. Coord. Chem. Rev. 1980, 33, 227-250.

(39) Freischmidt, G.; Michell, A. J. Performance of zircoaluminate coupling agents in wood flour/fibre-polyolefin composites. Polym. Int. 1991, 24, 241-247.

(40) Staal, B. Characterization of (co)polymers by MALDI-TOF-MS. Thesis, Technische Universiteit Eindhoven, Eindhoven, The Netherlands, 2005.

(41) Tettey, K. E.; Lee, D. Effect of thermal treatment and moisture content on the charge of silica particles in non-polar media. Soft Matter 2013, 9, 7242-7250.

(42) Lopez, T.; Ortiz, E.; Alvarez, M.; Navaarrete, J.; Odriozola, J. A.; Martinez-Ortega, F.; Páez-Mozo, E.; Escobar, P.; Espinoza, K. A.; Rivero, I. A. Study of the stabilization of zinc phthalocyanine in sol-gel $\mathrm{TiO}_{2}$ for photodynamic therapy applications. Nanomed. Nanotechnol. 2010, 6, 777-785. 